\title{
Os Estados Unidos e a região do Magreb-Sahel: securitização, militarização e terrorismo
}

\author{
Rodrigo Duque Estrada* \\ Fernando Preusser de Mattos ${ }^{* *}$
}

\section{Resumo}

O presente trabalho tem como objetivo identificar o atual processo de securitização das regiões do Magreb e do Sahel à luz da macro-securitização engendrada pela Guerra Global ao Terror (GGT), a qual, após o 11/09, redefiniu a agenda global de segurança. Primeiro, será apresentada uma introdução à teoria da securitização proposta pela Escola de Copenhague. Segundo, será abordado o conceito teórico de macro-securitização, enquadrando-o ao escopo da GGT. Terceiro, será analisado o processo de securitização do Magreb-Sahel, sendo apontadas as suas dinâmicas específicas. Quarto, será apresentada uma análise sobre as contradições imanentes ao atual método empregado no combate ao terrorismo na região. Por fim, será apresentada uma perspectiva histórica que revela as origens do terrorismo na região - na dialética repressão-radicalização -, o que evita tratar o objeto em questão como uma categoria apriorística de análise.

Palavras-Chave: Securitização; Magreb; Sahel; terrorismo; Mali.

\section{Abstract}

The United States and the Maghreb-Sahel region: securitization, militarization, and terrorism

The following work discusses the current securitization process of the Maghreb and Sahel regions, in the light of the macro-securitization engendered by the Global War on Terrorism (GWOT), which redefined the global security agenda after 09/11. First, the work presents an introduction to the theory of securitization proposed by the Copenhagen School. Then, it approaches the theoretical concept of macro-securitization, framing it to the scope of the GWOT. It then analyzes the securitization process in the Maghreb-Sahel, assessing its specific dynamics. Next, it further analyzes the immanent contradictions to the current methods employed against terrorism in the regions. Finally, it presents a historical perspective discussing the origins of terrorism in the region - associated with the repression-radicalization dialectics -, which avoids treating the object at issue as an aprioristic category of analysis.

Key-words: Securitization; Maghreb; Sahel; terrorism; Mali.

\footnotetext{
* Graduando em Relações Internacionais na Universidade Federal do Pampa (UNIPAMPA). Email: rodpanzera@gmail.com.

** Mestrando em Ciência Política pela Universidade Federal do Rio Grande do Sul (UFRGS) e graduado em Relações Internacionais na mesma instituição. Email: preusser.fernando@gmail.com.
} 


\section{Introdução}

As regiões do Magreb - Marrocos, Tunísia, Argélia e Líbia - e do Sahel - Mali, Chade, Níger e Mauritânia - localizam-se ${ }^{1}$, respectivamente, a norte e noroeste da África, abrangendo grande parcela do deserto saariano e sendo depositárias de importantes recursos naturais como petróleo, fosfato, gás natural, urânio, entre outros. Tradicionalmente marginal à discussão da política internacional, o MagrebSahel foi subitamente transformado em objeto de interesse das relações internacionais, despertando grande atenção entre formuladores de política e analistas. O presente artigo tem como objetivo identificar o novo status geopolítico do MagrebSahel sob a perspectiva do processo de securitização que ocorre na região, que se tornou central para a Guerra Global ao Terror (GGT) iniciada pelos Estados Unidos da América (EUA) após os atentados do 11/09.

A crescente presença dos EUA na região, além de interesses comerciais e econômicos, baseia-se na identificação do deserto do Saara como um local potencial de refúgio e treinamento de grupos terroristas ligados ao fundamentalismo islâmico. Rebeldes vinculados à Al-Qaeda no Magreb Islâmico (AQMI), suposta rede terrorista afiliada à Al-Qaeda, bem como outros agrupamentos regionais e mesmo locais estariam ameaçando a estabilidade e a soberania dos países na região e, por extensão, a própria segurança dos países ocidentais. Programas militares sucessivos foram criados, por parte dos EUA, para combater células terroristas no deserto do Saara. No entanto, devido a características específicas do Magreb-Sahel, o envolvimento dos países ocidentais no combate ao terrorismo confronta um paradoxo essencial: ao querer promover a democracia e os valores liberais, o ocidente parece reforçar regimes autoritários da região. Assim, a pesquisa concentra-se na securitização como processo político para justificar a percepção de uma ameaça existencial (os terroristas) como mais emergencial que outras (corrupção, Estado fraco, pobreza). Primeiro, será

\footnotetext{
${ }^{1}$ Doravante, estas regiões serão referidas como uma unidade única de análise - como uma só região, portanto.
} 
apresentada uma introdução à teoria da securitização conforme proposto pela Escola de Copenhague. Segundo, será abordado o conceito de macro-securitização, enquadrando-o ao escopo da GGT. Terceiro, será analisado o processo de securitização do Magreb-Sahel, apontando suas dinâmicas específicas. Quarto, será apresentada uma análise sobre as contradições imanentes à atual metodologia empregada no combate ao terrorismo na região. Por fim, será apresentada uma perspectiva histórica que revela as origens do terrorismo na região.

\section{Introdução à Teoria da Securitização}

A teoria da securitização, desenvolvida nos trabalhos da Escola de Copenhague, refere-se ao processo em que uma questão é apresentada em termos de "segurança", isto é, como uma ameaça existencial urgindo medidas extraordinárias para combatêla. Conforme seus expoentes, um conceito não possui significado intrínseco, a priori, e é a partir desta premissa que Waever (1995) inicia a desconstrução do conceito de segurança. Segundo a teoria, o termo "segurança" não pode ser tratado como uma condição objetiva de análise, mas como resultado de um processo social específico, ou seja, trata-se aqui de compreender a construção social das questões de segurança (Williams, 2003, p.513). Isto implica dizer que "segurança", tal como se entende convencionalmente, representa a reificação de um campo de práticas específicas. Segundo Waever (1995), a especificidade da segurança deve ser encontrada "in the field and in certain typical operations within the field [...] not in a clearly definable objective [...] or a specific state of affairs [...]" (p.70).

Ao afirmar que ameaças são politicamente construídas, não se pretende negar que uma ameaça de facto exista, mas que, no processo de securitização, certas questões podem ser transformadas em (e percebidas como) ameaça onde esta não existe, e em detrimento de outras que podem apresentar riscos ("ameaças") efetivamente reais.

O que é, contudo, "segurança"? De acordo com Waever (1995), "segurança" é um ato de linguagem. Isto não quer dizer que o ato faça referência a uma ameaça real, mas que a declaração (utterance) de que algo representa uma ameaça é, em si, o ato, pois, em consequência da declaração, algo é realizado, tornando o discurso a realidade 
primária: "By uttering "security," a state-representative moves a particular development into a specific area, and thereby claims a special right to use whatever means are necessary to block it" (p.73). Nesse sentido, a securitização refere-se a um nível específico da política por onde certas questões passam a ser designadas como ameaças existenciais e, portanto, demandam um estado de exceção, uma suspensão da política normal, justapondo-se acima desta, de modo que a ameaça possa ser prioritariamente combatida por meio da mobilização de recursos que, de outra maneira, seriam impossíveis de se obter.

Operacionalmente, $\mathrm{o}$ ato de linguagem da securitização depende de três fatores interdependentes: 1) o ator securitizador, isto é, quem realiza o ato, apresentando algo como uma ameaça dentro de uma retórica gramatical específica de segurança; 2) o objeto de referência da segurança, ou seja, aquilo em nome de que a securitização visa defender; e 3) a audiência, aquela para a qual o ato de linguagem é justificado, em outras palavras, a coletividade que legitimará (ou não) a securitização de uma questão. A articulação entre tais fatores evidencia o caráter essencialmente intersubjetivo da teoria da securitização (Tanno, 2003, p.57).

A teoria inclui hoje contribuições renovadas de outros campos, como da linguística, da antropologia e dos debates sobre ética. A tendência mais inovadora encontra-se na área das comunicações, estendendo a análise do processo securitizador para além do ato de linguagem discursivo-verbal, incluindo o papel crescente que os tipos de comunicação política contemporânea - envolvendo televisão, filmes, mídias digitais etc. - representam num mundo saturado de imagens (Williams, 2003; Coşkun, 2012). Além de ampliar o escopo de análise para as múltiplas formas de recepção imagética de uma determinada audiência, tal abordagem permite explorar melhor o conteúdo ideológico que assume a forma da securitização quando, por exemplo, o objeto de referência é a identidade de uma nação ou a defesa de princípios universais como o liberalismo, operadas dentro do setor societal ${ }^{2}$.

\footnotetext{
${ }^{2}$ A Escola de Copenhague se insere na tendência de alargamento e aprofundamento do conceito de segurança. Isto implica que a subárea "Estudos de Segurança Internacional" não deva se restringir ao
} 


\section{A macro-securitização da Guerra Global ao Terror}

A Escola de Copenhague concentrou-se inicialmente em securitizações de nível médio, onde os atores (quase sempre Estados) constroem suas questões de segurança uns contra (ou com) os outros. O nível médio de análise tornou-se frequente devido ao maior grau de coesão de suas unidades politicas correspondentes, na medida em que permanece o Estado-Nação como o mais alto axioma da vida política internacional. Nesse sentido, a primeira e terceira imagens das teorias de RI (nível individual e sistêmico, respectivamente) receberam pouca atenção devido à maior dificuldade de securitizar questões em tais níveis. No entanto, recentes elaborações da Escola de Copenhague ampliaram o escopo de análise para reconhecer "larger scale patterns where a set of interlinked securitisations become a significant part of the social structure of international society." (Buzan \& Wæver, 2009, p.256).

Durante a Guerra Fria, a securitização das ameaças socialistas, por um lado, e as liberais, por outro, elevou o padrão das questões de segurança ao nível sistêmico, onde os objetos de referência passaram a estar menos ligados ao Estado (defesa nacional) do que às ideologias universais da estrutura bipolar. A esse movimento que envolve a defesa de objetos de referência acima do nível médio, a Escola de Copenhague cunhou o termo macro-securitização. A macro-securitização incorpora e coordena múltiplas securitizações de níveis menores, hierarquizando-as, como no caso Guerra Fria, ou simplesmente amalgamando-as, como parece ocorrer no caso da Guerra Global ao Terror (GGT) com a securitização das drogas, do crime e das armas de destruição em massa (Idem, p.257).

Em seguida aos ataques terroristas de 11/09, os EUA declararam formalmente ao mundo a GGT. Com a ascensão dos neoconservadores ao poder, representados pelo ex-presidente Bush, Washington embarcou numa "estratégia multidimensional na qual se misturaram ações militares, políticas, econômicas e diplomáticas em alianças com organizações internacionais e países-chave" (Pecequilo, 2011, p.385). Para além do atentado em si, o 11/09 marcou simbolicamente o fim de um período de incertezas característico do pós-Guerra Fria: a década de 1990 evidenciava um déficit de ameaça

setor militar como fonte de análise convencional. Nesse sentido, a aplicação dos estudos de segurança abrangeria outros setores, como político,econômico e societal. 
para os EUA, sobre a qual pudesse assentar sua liderança internacional, num período de transição que acenava um relativo declínio de sua hegemonia.

Após sucessivas tentativas de encontrar um novo inimigo ${ }^{3}$, nenhuma ameaça foi tão essencial à política externa dos EUA como a do terrorismo. Conforme Buzan (2006),

\begin{abstract}
The rhetorical move to the concept of a 'long war' makes explicit what was implicit in the GWoT from its inception: that it might offer Washington a dominant, unifying idea that would enable it to reassert and legitimize its leadership of global security[...] If it could be successfully constructed and embedded as the great new global struggle, it would also underpin the shaky legitimacy of US unipolarity, maintenance of which was a key goal in the US National Security Strategy (USNSS) of 2002 [...] (p.1101).
\end{abstract}

O 11/09 desencadeou uma redefinição da agenda de segurança internacional, tornando o combate ao terrorismo uma prioridade de segurança reverberada por diversos países e organizações internacionais. Segundo Cunha (2009), "a estrutura do combate ao terrorismo internacional atingiu [...] níveis de institucionalização, cooperação e consentimento que permitem sua classificação como um regime internacional" (p.26).

A concepção de regime internacional antiterrorista, embora empiricamente verificado, não é suficiente para dar conta da GGT enquanto macro-securitização. Nesse sentido, é importante centrar-se nos elementos-chaves da teoria da securitização, agora em escala e dinâmica maiores. Assim, a macro-securitização sustenta o mesmo princípio de ameaça existencial que requer meios excepcionais para combatê-la, entretanto, opera-se num campo diferenciado, por se tratar do nível sistêmico de análise.

Um primeiro aspecto da macro-securitização da GGT é a forma pela qual se torna possível a coordenação de políticas de segurança antiterroristas entre diversos países, a despeito das divergências acerca do termo "terrorismo" e o uso que se faz deste. Nesse sentido, há benefícios entre as unidades, que se apropriam da questão

\footnotetext{
3 "[F]irst Japan, then China, 'clash of civilizations' and rogue states" (Buzan 2006, 1101). Para maiores detalhes, Cf. Pecequilo (2011), principalmente os capítulos 6 e 7.
} 
securitizada para resolver seus próprios problemas internos (Buzan \& Wæver, 2009, p.266).

Segundo, há uma tendência na GGT de associar outros tipos de securitização à narrativa específica do terrorismo, potencializando e expandindo o movimento securitizador às adaptações políticas das unidades. Assim, o tráfico de drogas, as armas de destruição em massa, a imigração, etc., encontram atualmente eco na GGT (Buzan, 2006, p.1104), tornando mais fáceis as medidas de combate, mesmo quando resultam numa simplificação extrema da realidade, como evidencia a securitização do MagrebSahel. Como apontam Buzan e Waever (2009), "[i]t becomes an aim in itself to be able to form one's security agenda under the heading of terrorism, whatever its actual content is" (p.267).

Terceiro, a macro-securitização da GGT atinge não somente a raison d'être das unidades políticas, redefinindo suas agendas de segurança, mas opera também num nível epistemológico, ou seja, na forma como o conhecimento é construído em sociedade, refletindo efeitos sobre políticas públicas no plano internacional. Na medida em que a securitização torna possível a construção de uma realidade "objetiva" relacionada ao terrorismo, sendo então legitimada e institucionalizada (Coşkun, 2012, p.42), a produção do conhecimento, quando tange o tema securitizado, ganha contorno de verdade científica, "edificada pelos jogos de poder e apropriada pelos governos, que utilizam canais formais e informais pra tal" (Teixeira, 2007, p.47). Assim, exemplificando, é interessante o debate sobre o desenvolvimento, cujo discurso está agora centrado no corolário segurança-terrorismo: se, após a Guerra Fria, o conceito de desenvolvimento passou a estar associado ao crescimento econômico dos países do sul, com o 11/09 houve uma súbita mudança de paradigma, passando a segurança (na luta contra o terrorismo) a servir como objetivo e instrumento do desenvolvimento, e invocando seu aspecto militarizado (Beall et al., 2006), reerguido dos escombros da Guerra Fria.

Quarto, o aspecto subjetivo da identidade ganha relevância na macrosecuritização da GGT. A habilidade de gerar uma macro-securitização bem sucedida depende da construção de objetos de referência de maior nível que sejam capazes de apelar para a política de identidade das unidades do sistema (Buzan \& Waever, 2009, 
p.268). A GGT apresenta-se como a defesa dos princípios universais dos EUA - em grande medida o rótulo ideológico adotado pelos discursos do ocidente. Os republicanos colocaram o tema do terrorismo como prioridade em sua agenda política, tornando o tema uma missão de fé, uma espécie de "renovação do Destino Manifesto, que coloca as ações norte-americanas como um dever e um direito, visando a proteção da liberdade e a sua disseminação" (Pecequilo, 2011, p.394). Portanto, a GGT apresenta uma macro-securitização onde a ideologia da Al-Qaeda é percebida como ameaça e aceita como tal pelo ocidente, inclusive no mundo muçulmano (Buzan, 2006, p.1103). Conforme Coşkun (2012), a retórica da GGT "caused the resurrection of colonial themes of civilized vs. barbarian by highlighting the terrorist threat to liberal universal principles of democracy, human rights and the market" (p.42).

A classificação de algo como "terrorista", portanto, evoca um arquétipo que prenuncia sua essência de ameaça, caos, irracionalidade e instabilidade, levando à conclusão de que, quanto mais se consiga enquadrar uma questão no código de linguagem específico do terrorismo, dentro da relação ator securitizador/audiência, mais bem sucedida será a (macro) securitização. Há diversos fatores que corroboram o movimento securitizador. No entanto, ao se falar da GGT, os atos de linguagens tradicionais (discursos proferidos por representantes de Estado) tornam-se insuficientes, uma vez que a audiência que legitima a securitização é transnacional, e para cuja recepção o movimento securitizador deve pautar-se em recursos mais abrangentes como a produção de conhecimento dos think tanks e o poder das imagens, que "[têm] a particularidade de poder produzir o que os críticos literários chamam de efeito de real. [...] ela[s] pode[m] fazer ver e fazer crer no que faz ver. Esse poder de evocação tem efeito de mobilização" (Bourdieu apud Teixeira, 2010, p.44). Como exemplo, Coşkun (2012) analisa o papel dos seriados populares de televisão, os famosos 24 e Spooks (produção norte-americana e britânica, respectivamente), cujas representações visuais sobre a GGT, ainda que ficcionais, têm tido "considerable influence on the public perception of the Islamic terror as an existential threat and on the legitimization of counterterrorism policies in the eyes of public" (p.49). 
Por fim, um úlimo aspecto da GGT deve ser ressaltado. Trata-se do caráter vago da macro-securitização; conforme Buzan e Waever (2009):

\begin{abstract}
A certain vagueness is probably often necessary for a macrosecuritization, especially when the threat is not manifest and material, and the US securitization of terrorism as a security threat has therefore been exceptionally loose in terms of referent object, threat and relationship between specific countermeasures and specific threats (p.266).
\end{abstract}

Nesse sentido, diferentemente do periodo da Guerra Fria, em que o inimigo apresentava-se de maneira bem definida, o inimigo da GGT é "abstrato e difuso" (Visacro, 2009, p.30), contendo também um caráter amorfo que é altamente funcional, facilitando seu uso político (Teixeira, 2010, p.52).

\title{
3. O Processo de securitização do Magreb-Sahel
}

Uma vez estabelecida a macro-securitização da GGT em diversas instâncias da sociedade internacional, sua aplicação prática nas esferas regionais revela diferentes padrões de adequação e entronização, trazendo à luz o conceito dos Complexos Regionais de Segurança (CRS), definido como um conjunto de unidades em que os "principais processos de securitização e dessecuritização [...] são tão interligados que seus problemas de seugrança não podem ser [...] analisados ou resolvidos de maneira separada" (Buzan apud Tanno, 2003, p.70).

Dentre as diversas frentes da GGT, cada qual respondendo a dinâmicas específicas, uma das mais recentes é a região do Magreb-Sahel. Historicamente, a política norte-americana para a região foi pouco expressiva, atendendo apenas a requisitos conjunturais. Em cada circunstância, tal política não refletiu a busca por uma esfera de influência sistemática (política, militar e econômica), senão aos interesses pelo estabelecimento e manutenção de relações bilaterais (Zoubir, 2008).

O cenário mudou abruptamente com o 11/09, quando os EUA passaram a identificar uma ameaça generalizada por todo o cinturão do Saara-Sahel, num contexto em que, seguindo o discurso oficial estadunidense, "[...] nowhere has interest and action on terrorism move[d] so rapidly in Africa recently than in the areas bordering the Sahara desert" (Lyman apud Thurston, 2010, p.52). Esta nova percepção 
de ameaça baseia-se numa confluência de fatores característicos da região, como atividades de grupos radicais islâmicos, o potencial desagregador dos Estados fracos, as parcelas do deserto não governadas que incluem zonas fronteiriças e a ideia de que tais características sejam atrativos para o refúgio de organizações terroristas (safe haven) e recrutamento da Al-Qaeda. Assim, e independentemente do fato do terrorismo - em sua forma conceitual tradicionalmente propagada - na região ser real ou não, pois, como se verá adiante, trata-se de uma realidade discursivamente exacerbada, a securitização é justificada sob o pretexto de prevenção (Mundy, 2010, p.5). Nesse sentido, conforme Archer \& Popovic (2007), a análise da situação não é tão clara:

threats, including terrorist threats, are constructed - this is very different to saying that they are not real - in certain ways [...] This is clearly happening in the Sahara and Sahel. The US has identified a threat in that region in the form of jihadi terrorists [...] and has set out to counter this threat, predominantly by military means. The construction of the threat in this way has very real implications for both US policy and the Saharan countries (p.8).

O processo de securitização teve início com o lobby intensivo de diversos grupos de interesse que defendiam maior presença militar dos EUA na África, principalmente por analistas políticos, jornalistas e think tanks simpáticos à GGT (Thurston, 2010; Isidoros, 2010; Archer \& Popovic, 2007). Respaldados pelo expresidente Bush, deu-se início à evolução de uma presença cada vez mais expressiva e sistemática dos EUA na região, desencadeando uma série de consequências e antíteses que, além de introduzir um processo de institucionalização da militarização estadunidense como matéria-prima de combate ao terrorismo, culminou na transformação da dinâmica de segurança do Magreb-Sahel ao construir uma rede de defesa militar antiterrorista na região ${ }^{4}$ (Solá-Martin, 2010, p.8; Zoubir, 2009, p.13).

\footnotetext{
${ }^{4} \mathrm{O}$ processo não ficou restrito aos atos de linguagem tradicionais, ganhando também conteúdo imagético de caracterização da região e seus habitantes. Considerando a indústria cinematográfica estadunidense, durante um longo período, os filmes de Hollywood de conteúdo político retratavam o governo dos EUA como hostil e corrupto, mas com a virada do 11/09, emergiu uma onda de patriotismo e apoio à GGT no cinema (Weinraub 2001) . Isidoros (2010) analisa o filme Sahara (lançado em 2005), produzido a partir de uma colaboração entre Hollywood e a administração Bush, que é um exemplo
} 
O primeiro órgão da militarização do Magreb-Sahel, iniciado em outubro de 2002, foi o Pan Sahel Initiative (PSI), programa de apoio logístico e treinamento militar contrainsurgente que incluiu os governos da Mauritânia, Mali, Níger e Chade. Sendo uma iniciativa do Departamento de Estado norte-americano e contando com um orçamento inicial de U\$ 7.75 milhões, o PSI foi arquitetado "[...] to enhance border capabilities throughout the region against arms smuggling, drug trafficking, and the movement of trans-national terrorists" (Global Security, s/p).

Controlado por uma das divisões de comando militar do EUA, o European Command (EUCOM), o PSI só não se estendeu a toda faixa saheliana por questões burocráticas, embora seja questionável o ponto até o qual havia evidência suficiente de atividades terroristas que justificassem sua implantação ${ }^{5}$ (Toby \& Archer, 2007, p.42). Só foi com o sequestro de 32 turistas europeus, em março de 2003, alegadamente perpetrado pelo Groupe Salafiste pour la Prédication et le Combat (GSPC), e eventos subsequentes, que o PSI passou a ter um fundamento sobre o qual pudesse justificar sua existência (Thurston, 2010, p.53). O programa encerrou suas atividades em 2004, conseguindo coordenar ações militares conjuntas com os quatro governos, cujo ponto máximo foi a longa perseguição pelo deserto - envolvendo os territórios da Argélia, Mali, Níger e Chade - de Ammed Saifi, líder da GSPC e alegado responsável pelos sequestros. Saifi foi capturado em 2004 no Chade, o que levou a EUCOM a fazer campanha no congresso dos EUA para aumentar o escopo e o orçamento do programa (Harmon, 2010, p.22).

Em decorrência, organizou-se um projeto militar de maior abrangência e conteúdo, o Trans-Sahara Counterterrorism Initiative (TSCTI) - reformulado posteriormente para Trans-Sahara Counterterrorism Partnership (TSCTP) - passando a incluir os países do Magreb, Marrocos, Tunísia, Argélia e Líbia, e também outros atores

claro dessa tendência e também didático para explicar a securitização do terrorismo no Magreb-Sahel, pois a narrativa constroi a dualidade maniqueísta dos heróis norte-americanos que salvam os tórridos desertos do oeste africano de uma epidemia ao derrubarem senhores de guerra que operam nos territórios pouco controlados do Saara (64). A despeito do filme, esse tipo de representação de um "vazio temeroso" do deserto do Saara (idem, 68) encontra eco nos discursos oficiais: de acordo com o oficial de relações públicas do Comando Europeu de Operações Especiais (SOCEUR, na sigla em inglês), Major Holly Silkman, trata-se na região o "Velho Oeste tudo de novo" (apud Harmon 2010, p.23).

${ }^{5}$ Os estudos e relatos oficiais do governo dos Estados Unidos sobre o terrorismo naquele período não faziam nenhuma referência aos quatro países do PSI. Para maiores informações, Cf. Toby \& Archer (2007). 
centrais à segurança regional como Nigéria, Senegal e Burkina Faso. Apesar do orçamento relativamente baixo do PSI/TSCTP (U\$ 100 milhões anuais para cinco anos) há de se considerar que a militarização do Magreb-Sahel não se limita estritamente a tais iniciativas, sendo senão uma de suas várias facetas. Pode-se argumentar, entretanto, que os referidos programas militares representaram uma porta de entrada para os EUA na região, uma forma de legitimar sua presença inclusive em todo continente africano.

O segundo mandato do presidente Bush marcou um novo tipo de engajamento no discurso antiterrorista. Após sucessivas pressões de lobby políticos que demandavam uma presença militar mais intensiva, a retórica democrática que vingou durante o período 2001-2005 foi deixada de lado, estando o desenvolvimento dos países do Magreb-Sahel definitivamente associado à estabilidade de seus regimes (Thurston, 2010, p.54). Cristalizada nesse movimento foi a proposta de criação de um comando militar unificado para toda a África, o AFRICOM. Criado em outubro de 2008, - AFRICOM é a nova grande fase da militarização não só do Magreb-Sahel mas também do continente africano. Contando com um orçamento de U\$ 276 milhões para o ano de 2012 e um amplo programa militar com vários comandos subordinados, a base de operações do AFRICOM está localizada em Stuttgart, Alemanha (AFRICOM, $s / p)$, sendo que nenhum país, com exceção do Marrocos, aceitou sediá-lo até o presente momento.

Um aspecto importante a ser destacado no processo de securitização do Magreb-Sahel é que a implementação de tais mecanismos de combate antiterroristas não representam uma política unilateralmente deliberada por parte do governo dos EUA, evidenciando um complexo emaranhado de atores e interesses envolvidos na questão que se sobrepõem ao quadro da GGT. Nesse sentido, entende-se que a securitização do Magreb-Sahel se deu mais no âmbito interno ao aparelho burcrático dos EUA do que em seu aspecto de convencimento amplo em sociedade. Isto porque, na relação ator securitizador-audiência, a legitimação da GGT já havia sido em grande medida obtida como resultado de sua macro-securitização; sua lógica foi incorporada à 
burocracia de Estado, cuja estrutura destina parcela expressiva de orçamento às diversas medidas de combate ao terrorismo. Assim, o que explica a securitização do terrorismo no Magreb-Sahel (qua militarização institucionalizada) são os atos de linguagem específicos intra-agência nos EUA que competem entre si pela obtenção de recursos escassos. Conforme analisam Toby e Popovic (2007),

[...] amongst Africa specialists within the US government, the most obvious way to attract the previously scant attention of Congress and the Administration is to raise the terrorist issue, in effect turning the Sahel/Saharan region from a development and diplomacy issue into a security issue [...] Since 9/11, an organisation's importance within the US government system has to a great extent been determined by its contribution to $[\mathrm{GGT}](\mathrm{p} .53)$.

Em termos práticos, o que impulsionou a criação do PSI/TSCTP foi a posição crescentemente marginal do EUCOM na política militar dos EUA, principalmente no tocante à GGT, em que o Central Command (CENTCOM), outra divisão geográfica de comando militar, vem desempenhando papel proeminente. Assim, o EUCOM teve que se impor por uma questão de sobrevivência institucional, a fim de não perder seu lugar na África e garantir recursos para lograr alcançar seus interesses (Idem, p.54)6. O que isso revela, portanto, é a intricada rede de poder nos EUA e a convergência entre os diversos atores envolvidos no processo de securitização do Magreb-Sahel, na medida em que a reivindicação do EUCOM por um espaço nesta região não é um fato a ser analisado de maneira isolada, mas um propulsor do projeto de aproximação dos EUA com os regimes daquela região e, por extensão, do continente africano.

Uma vez identificado o parâmetro de ação da GGT no Magreb-Sahel, podem-se apontar as dinâmicas específicas que conformam a securitização regional, bem como analisar as contradições geradas a partir de sua estrutura.

\footnotetext{
${ }^{6}$ Um dos objetivos auto-declarados do PSI foi o de "to bolster EUCOM's interest in the regional" (Global Security, $s / p$ ). Tal declaração faz com que ganhe relevância o argumento sobre a securitização burocrática, isto é, os atos de linguagem específicos inseridos em um contexto de atores e interesses de diferentes agências de Estado (e também além-Estado) nos EUA que competem entre si pela obtenção de recursos escassos. Ainda, ao confrontar tal argumento com o fato de que não havia evidência de atividades terroristas na região, pode-se problematizar ainda mais a questão do sequestro dos 32 turistas europeus, o qual, segundo Jeremy Keenan, teria sido uma fabricação do serviço de inteligência argelino com apoio dos EUA (apud Archer \& Popovic 2007, 30-32).
} 


\section{Contradições da Guerra Global ao Terror no Magreb-Sahel}

Um primeiro fator a ser identificado diz respeito às relações bilaterais dos EUA com os regimes do Magreb-Sahel após o início da GGT. De fato, tais iniciativas militares acima referidas colaboraram para que os EUA cimentassem suas relações com regimes que servem aos seus interesses geopolíticos (Toby \& Popovic, 2007, p.36). Assim, países com os quais os EUA mantiveram-se relativamente afastados antes, como Argélia, Mauritânia e Líbia, tiveram suas relações com Washington subitamente transformadas com o advento da GGT (Zoubir, 2008). Aos países que já eram aliados, este movimento representou uma consolidação de suas relações com os EUA. Por exemplo, no caso do Marrocos, seu apoio na GGT garantiu-lhe recompensa sob forma de um tratado de livre-comércio e a condição de aliado não-membro da OTAN, ambos no ano de 2004 (Zoubir, 2009, p.7).

Com o estreitamento dos eixos bilaterais e a construção de uma rede transnacional de combate ao terrorismo no Magreb-Sahel, cada regime, como consequência, passou a ser beneficiado de maneira particular no processo de militarização da região, apropriando-se do quadro da GGT para securitizar seus problemas internos. Tais regimes se utilizaram da GGT, portanto, como argumento para intensificar a segurança interna e reprimir a oposição. A Argélia, entretanto, foi a que mais se beneficiou desse processo. Segundo Henry (2008),

The GWOT serves the regime in two ways. It justifies a continued state of emergency at home, enabling the regime to bottle up protest, and it wins the regime a measure of international legitimacy, or at least dampens external criticism of its human rights abuses (p.298).

A Mauritânia também demonstrou saber utilizar-se bem das "rendas estratégicas" da GGT (idem). O ex-presidente Maaouya Ould Taya, que ascendeu ao poder em 1984 através de um golpe de Estado, passou a aliar-se no combate ao terrorismo. De acordo com Toby e Popovic (2007),

[o]nce allied to the US, the Ould Taya regime, despite being at least nominally the government of an Islamic state, denounced all the opposition it 
faced as "Islamist" and since the beginning of the PSI [...] in 2002 they also began to claim that opponents were linked to the GSPC and even al-Qaeda [...] (p.21).

Taya foi derrubado por um golpe militar em 2005, sob a alegação de instabilidade política como decorrência dos atentados terroristas que o país então sofria. No entanto, não tardou muito até que, após uma derradeira experiência democrática, um novo golpe levasse o General Mohamed Ould Abdel Aziz ao poder, em 2008, representando um verdadeiro desafio para a forma como os EUA deveriam promover sua política para a região. Inicialmente contrários ao golpe e baseando-se em um discurso democrático, o governo dos EUA logo sentiu necessidade de mudar o tom das críticas à Nouakchott em favor da estabilidade do regime e cooperação contraterrorista (Thurston, 2010, p.56).

O caso do Marrocos é também exemplar. Desde 1975, o Reino marroquino ocupa ilegalmente o território do Saara Ocidental, fato que tem impedido a realização de um referendo para a autodeterminação do povo autóctone - os saarauis conforme protegido pela Organização das Nações Unidas (ONU) desde a década de 1960. A despeito da pressão internacional cada vez maior para que o Marrocos se retire do território e cesse com a exploração dos recursos naturais, a estratégia utilizada pelo Reino como tentativa de desviar a atenção dos problemas internos de seu país (desemprego, repressão, pobreza, etc.) e da comunidade internacional, a fim de conquistar apoio à anexação do território, tem se dado em grande medida pelo mecanismo da securitização. Trata-se, na verdade, de uma apropriação das macrosecuritizações da Guerra Fria e da GGT, utilizando-as em benefício próprio, na tentativa de caracterizar o movimento de resistência saaraui, a Frente Polisário, como uma ameaça existencial ao Marrocos e, por extensão, aos interesses dos EUA.

Enquanto antes, no período da Guerra Fria, os saarauis eram considerados inimigos pelo suposto potencial de influência socialista que a região apresentava mesmo que os saarauis nunca obtiveram apoio da União Soviética - com a GGT, a "ameaça" passou a rotular-se sob o discurso do terrorismo, onde o Reino difunde a ideia de que os acampamentos de refugiados, onde vivem os saarauis, estão infiltrados de células terroristas da AI-Qaeda (Isidoros, 2010, p.64; Solá-Martin, 2010, p.9). E este tipo de propaganda se torna mais eficiente na medida em que se tem a figura 
centralizadora do Rei, o "Comandante dos Crentes", como articulador da nação entre toda a sociedade: "His power is sacred and his actions are rarely criticized publicly. The religiosity of the King is one of the most important components of its political communication" (Novotný et. al, 2011, p.16).

Por sua vez, a crise que levou à intervenção francesa na República do Mali, em janeiro de 2013, insere-se em um contexto de complexas relações, que subjazem ao recente aumento das pressões por parte dos EUA e da França especialmente quanto à ameaça existencial representada pelos rebeldes da Al-Qaeda no Magrebe Islâmico (AQMI) no norte do país. Primeiramente, conformam a situação contemporânea do país tanto a marginalização econômica, quanto a exclusão do processo político de determinados grupos populacionais, como os tuaregues, pelas elites desde a independência em 1960.

Além disso, a precária qualidade, senão completa inexistência, de aparelhos do Estado, especialmente na região norte do Mali, tem historicamente comprometido as condições de vida da população, acentuando a criminalidade e a impunidade e lançando as bases para que o fundamentalismo tenha se tornado uma alternativa política local (Lohmann, 2011). A maneira como o país encontra-se inserido no processo de militarização da região acrescenta mais um fator de complexidade aos conflitos em curso. O combate ao tráfico, um dos objetivos das políticas contraterroristas dos EUA na região, acaba também invariavelmente afetando o comércio intrarregional, do qual dependem muitos tuaregues. A intensificação do contraterrorismo, por sua vez, infligiu pesadas perdas nas receitas oriundas do setor de turismo, atingindo, sobretudo, as comunidades tuaregue e árabe (Mundy, 2013).

Em diversos momentos, no entanto, alguns fatores de catálise concorreram para o agravamento e para a sobreposição de conflitos simultâneos, culminando com os eventos que se desenvolvem no presente. Destacam-se o apoio concedido historicamente aos tuaregues pelo regime de Muammar al-Gaddafi, cuja deposição, em outubro de 2011, levou ao êxodo de tuaregues que lutavam junto às suas forças, os quais retornaram ao Mali fortemente armados e formaram o Movimento Nacional 
pela Libertação do Azawad (MNLA) (Sanders \& Moseley, 2012). Este, por sua vez, estabeleceu relações com grupos radicais islâmicos, tais como jihadistas da AQMI e do Movimento para Unidade e Jihad na África Ocidental (MUJAO), ambos associados de alguma forma ao Ansar Dine, pelo controle da região norte do país (Sanders \& Moseley, 2012; Archer \& Popovic, 2007; Lohmann, 2011).

Paralelamente, um quadro de completa deterioração do exército malinês levou ao golpe de Estado de 22 de março de 2012, pouco mais de um mês antes das eleições presidenciais, refletindo a insatisfação de setores militares em relação a uma governança decadente há anos (Théroux-Bénoni, 2013). Em decorrência do golpe, uma junta militar liderada pelo capitão Amadou Sanogo assumiu o poder em Bamaco e passou a coordenar a arquitetura institucional da transição antes das próximas eleições. Diante da grave situação no norte do país, a reestruturação e a reorganização das forças de defesa e de segurança, bem como a restauração da autoridade do Estado sobre aquela região tornaram-se prioridades imediatas do governo transitório, o qual, todavia, carecia de reconhecimento e de legitimidade perante à CEDEAO (ISS 2012). Inicialmente, a junta militar opunha-se - indo de encontro à posição da CEDEAO - a qualquer intervenção de tropas estrangeiras no Mali, garantindo ser possível reconquistar as cidades do norte ocupadas pelos rebeldes (Théroux-Bénoni, 2013).

No entanto, desenvolvimentos que ocorreram ao longo de 2012 alteraram esse panorama e conformaram a conjuntura que hoje se observa no país: por um lado, assistiu-se ao avanço dos grupos islâmicos MUJAO, Ansar Dine e AQMI no norte, paralelamente à marginalização do movimento tuaregue MNLA e à intensificação, por parte deste, das reivindicações pela autodeterminação do território do Azawad; por outro, intensificou-se o diálogo de mediação entre os organismos regionais CEDEAO e União Africana e a junta militar de Bamaco, tendo sido aprovada unanimemente pelo Conselho de Segurança das Nações Unidas a resolução 2056, em 5 de julho. Esta urgia o estabelecimento de um road map para o restabelecimento da ordem constitucional e considerava a proposta de envio de uma força de estabilização pela CEDEAO, cuja autorização viria, em 20 de dezembro, por meio da resolução 2085, autorizando o emprego da Missão Internacional de Apoio ao Mali sob Liderança Africana (AFISMA, na sigla em inglês) por um ano (ISS 2012; Théroux-Bénoni, 2013). 
Contudo, a tomada da cidade de Konna pelos grupos rebeldes do norte, em 10 de janeiro de 2013, acelerou os eventos e alterou definitivamente a conjuntura. Em um momento em que a reorganização e o treinamento do exército do Mali pela União Europeia não haviam começado, e no qual a AFISMA era incapaz de entrar em operação, o apelo do governo provisório à França e o início da Operação Serval inseriram um novo ator no contexto de crise e deram início a novas dinâmicas políticas e securitárias tanto no país como na região.

Conforme discutido, a questão do Mali não apenas ilustra a continuidade dos processos de militarização e de securitização do terrorismo na região, como acrescenta dinâmicas novas a esse processo que, seguindo a discussão das seções anteriores, se desenvolve dentro do contexto da macro-securitização engendrada pela GGT. Como pano de fundo, impõem-se, primeiramente, os evidentes interesses estratégicos das potências ocidentais na região, sobretudo dos EUA e da França.

Percebe-se, portanto, como os países se utilizam do rótulo do "terrorismo" para suprimir forças oposicionistas internas e justificar suas próprias medidas de exceção ao engajar-se na GGT. A militarização do Magreb-Sahel não pode ser considerada um fenômeno gratuito no qual os mais variados atores são passivos às transformações que estão atualmente em curso na região. Assim, o processo securitizador não pode ser desenvolvido sem deparar-se com contradições imanentes à sua estrutura. A questão-chave que se coloca é a de que, ao buscar combater o terrorismo por meio da estabilização dos países do Magreb-Sahel, os EUA incorrem no sentido inverso da retórica democrática, e assim a contradição se torna clara: a cooperação transnacional antiterrorista fortalece a capacidade de regimes que utilizam da coerção para manter-se no poder e que têm um longo histórico de violação dos direitos humanos (Solá-Martin 2010, p.8). Dito de maneira objetiva, todos os países da região são, em graus variados, autoritários (Harmon, 2010; Novotný et. al, 2011; Zoubir, 2009; Entelis, 2008).

O apoio a tais regimes implica a continuação da estrutura política desses Estados que, por mais que suas economias e forças produtivas sejam fracas e 
descoladas da sociedade, são beneficiados pelo que Entelis (2008) chama de saúde fiscal, decorrente das rendas de petróleo, gás natural, ajuda externa, turismo, remissões, etc., e que mantém uma relação diretamente proporcional com a capaidade coercitiva dos mesmos (p.12). Pode-se deduzir, portanto, que, cooperando militarmente com tais regimes, perpetuar-se-à a mesma estrutura que os sustenta, pois, segundo o mesmo autor, os aparatos de segurança do Magreb são uma instituição (a Mukhabarat) que serve como bastião das elites e guardiã dos interesses dos regimes (Idem, p.14).

Enfim, esse tipo de cooperação reflete um dilema pontual que os EUA vêm confrontando no mundo árabe, entre promover democracia ou manter a estabilidade dos regimes. Isto é devido ao fato de que um processo de democratização efetivo mais provavelmente levará ao poder partidos islâmicos de oposição, alguns dos quais são anti-ocidentais e que poderiam pôr em jogo os interesses geopolíticos dos EUA. Conforme Zoubir (2008),

[...] with respect to the Maghreb, as in the rest of the Arab world, the question that arises for US policy makers is how to encourage these friendly governments to participate in a genuine democratic process when such a process would undoubtedly bring to power Islamist political parties (p.271).

\section{A Dialética Repressão-Radicalização}

A militarização e a securitização do terrorismo no Magreb-Sahel, ao privilegiarem um foco de segurança estritamente militar para "estabilizar" a região, repercutem de maneira negativa gerando maiores contradições. Há um estabelecido consenso entre alguns analistas de que o terrorismo no Magreb-Sahel, embora real, não representa uma ameaça com alcance e força tão eminentes, tendo limites e constrangimentos bem definidos (Toby \& Popovic, 2007, p.47; Le Sage, 2011, p.5; Harmon, 2010, p.1). Entretanto, a securitização pode bem ser um agente de desestabilização crônica da região. Devido à imagem de "grande inimigo" que os EUA sustenta entre grande parcela da sociedade no mundo árabe, sua presença militar pode reforçar cada vez mais o ódio entre a população do Magreb-Sahel (Zoubir, 2008, p.266). Nesse sentido, há uma preocupação de que, com a presença dos EUA e seu apoio incondicional aos regimes da região, haja de fato uma maior inclinação ao 
radicalismo islâmico (Le Sage, 2011, p.11). Como aponta Zoubir (apud Harmon, 2010), "[i]f you treat it from a solely security perspective, you're producing more jihadists" (p.25).

Portanto, deve-se questionar a priorização da militarização como medida sustentável para que se alcancem a democratização e o desenvolvimento da região. Conforme sintetizam Toby e Popovic (2007),

The US military presence may well be an agent of instability in northwest Africa, exacerbating pre-existing tensions between minorities and national governments, and creating more anti-Americanism in a part of the Muslim world that previously was not inclined against the US. There is a danger that military counter-terrorism in the Sahara is a self-fulfilling prophecy: that a previously peripheral and small group - the GSPC, which is probably somewhere between a jihadi-terrorist group and a common criminal gang (and may well be being manipulated by the intelligence services of the regional power), is being given a status and importance that it does not deserve. It could even become the locus of resistance to what some in the region see as US imperialism. The securitization of the Sahara may bring some benefits, particularly for the governments of the region, but it also involves many costs that do not currently seem either well understood or admitted to by the commanders of EUCOM (p.59).

Nesse sentido, deve-se também problematizar: de onde surge o terrorismo como fenômeno na região do Magreb-Sahel? A ausência de tal perspectiva crítica faz com que o combate ao terrorismo assuma uma forma apriorística de identificação de uma ameaça em detrimento de outras, quiçá mais importantes. Assim, sem que se considerem as raízes históricas do terrorismo, o que revelaria métodos qualitativos de combate inteiramente adversos do atual propugnado, busca-se erradicá-lo justamente apoiando as instâncias que o reforçam, reproduzem e reificam: a cooperação com regimes autoritários da região e o aspecto militarizado da segurança, fazem repercutir uma imagem cada vez mais negativa dos EUA regionalmente, além do fato de representarem riscos potenciais ao desenvolvimento das sociedades locais, a exemplo dos nômades que habitam o Saara (Solá-Martin, 2010, p.8).

Com relação às raízes históricas que subjazem à situação comum aos países da região, considerando as condições sob as quais se estruturam politicamente os Estados 
da região ${ }^{7}$, Storm (2009) aborda os elementos daquilo a que se refere como o ciclo vicioso da repressão e da radicalização, ressaltando as ligações entre o autoritarismo que, desde a independência, caracteriza os sistemas políticos da região, e a radicalização da oposição aos regimes instituídos. As estratégias às quais os diferentes regimes da região recorreram, ao longo das décadas, para alijar seus opositores e, assim, manter-se no poder resumem-se, conforme a autora, à cooptação e à repressão, em um ambiente onde persiste a inexistência de eleições democráticas: em países como Argélia, Egito, Líbia, Marrocos e Tunísia, movimentos de oposição moderados foram historicamente cooptados pelo regime, ao passo que movimentos oposicionistas mais radicais viram-se relegados à ilegalidade e à completa exclusão do sistema político. Diante desse quadro de cooptação e da impossibilidade de competição eleitoral, a oposição nos países do Magreb-Sahel acaba ou recorrendo a uma abordagem anti-sistêmica, reunindo-se em movimentos islâmicos genuinamente de oposição e ilegais - isto é, não cooptados pelos regimes - ou então emigra para a Europa, atitude considerada pela autora também como forma de radicalização.

Associam-se à repressão praticada pelos regimes autoritários da região, no entanto, outros elementos decisivos que acabam compelindo a dissidência à radicalização, como a marginalização social e econômica e a alienação cultural (Entelis, 2008). Assim, diversos movimentos anti-sistêmicos organizaram-se como consequência da repressão imposta pelos regimes autoritários, da inviabilidade de ação política dentro do sistema autoritário e da precariedade de condições de vida. Os movimentos Justiça e Caridade no Marrocos, Grupo de Combate Islâmico Líbio (LIFG, na sigla em inglês) e a Irmandade Muçulmana, no Egito, representam, segundo Storm (2009), alguns dos opositores islâmicos mais representativos da região. Além disso, a questão dos tuaregues no Mali e o caso do GSPC, da Argélia ${ }^{8}$, assim como diversos

\footnotetext{
${ }^{7}$ A configuração política da região remete, originalmente, às delimitações fronteiriças arbitrárias do imperialismo europeu, catalisadoras, portanto, de grande parte das tensões étnicas e da divisão do poder no continente africano.

8 Produto da longa guerra civil argelina e da evolução de movimentos islâmicos marginalizados pelo regime, o GSPC surgiu em 1998 como dissidência de grupos armados islâmicos que não apenas combatiam o regime, como também se enfrentavam mutuamente. $O$ grupo expandiu sua atuação para os demais países do Sahel ao longo da década de 2000, obteve recursos através de sequestros, contrabando de armas, pessoas e produtos e da extorsão de traficantes de drogas da região, passando a integrar-se formalmente à rede internacional da Al-Qaeda em 2007, com sua denominação então
} 
movimentos nos demais países do Magreb-Sahel, inserem-se, em geral, nessa mesma lógica.

\section{Conclusão}

O presente trabalho buscou identificar os processos de militarização e de securitização do terrorismo atualmente em curso na região do Magreb-Sahel, dentro do escopo da macro-securitização da GGT. Não obstante as contradições deste processo já exploradas, alguns pontos permanecem abertos e merecem breve discussão.Um dos aspectos mais importantes para a teoria da securitização gira em torno da construção das identidades no campo societal de segurança. A securitização é considerada como política enraizada na identidade do "eu" e do "outro", pois é a semelhança e a diferença que estão no cerne da questão (Buzan \& Wæver, 2009, p.261). Como aponta Coşkun (2012),

[...] it makes little sense to speak of one's security without recognizing the source of the threat, 'the other'. In the absence of 'the other' one cannot speak about security [...] In this sense, securitization is about the process through which a state/society is consolidated vis-à-vis an enemy-other $[\ldots]$ (p.39).

Pode-se transpor tal argumento para o objeto aqui analisado: a relação "eu" e "outro" se dá na dualidade "ordem" (Estados ocidentais e seus valores intersubjetivos) e "caos" (os terroristas não-estatais). Assim, por ser a securitização uma prática relacional de identidades, tem-se que é também performática, no sentido de que ambos, "eu" e "outro", "caos e "ordem", são identidades ontologicamente dependentes, mutuamente constitutivas, negando-se, portanto, a ideia de que a

alterada para AQMI (Harmon 2010). No entanto, prevalece entre os analistas a percepção de que a filiação desse movimento originariamente argelino à Al-Qaeda constituiu muito mais uma manobra do próprio grupo a fim de garantir sua sobrevivência enquanto movimento radical - e angariar reputação internacional - do que propriamente um passo adiante na busca pela deposição do governo argelino ou pela propagação da jihad global (Harmon 2010; Lohmann 2011; Le Sage 2011). 
"nação" - entendida em sentido amplo - seja um sujeito autônomo, apriorístico e objetivo:

\begin{abstract}
A performative approach shows that "crisis" is not an objective condition that threatens the viability of the nation-state per se, but rather an ascriptive category that generates the identity of the actor that does the actual ascribing. The State [ou "ordem"] and "crisis" [...] are the mutually dependent products of discursively produced binary oppositions (Feldman, 2005, p.216).
\end{abstract}

O que se pretende com esta abordagem performática é mostrar que, na medida em que a identificação de uma ameaça reifica a identidade da nação (Williams, 2003, p.519; Feldman, 2005, p.215), a securitização envolve processos mais sutis que são geralmente velados. Nesse sentido, uma problematização torna-se essencial: qual o verdadeiro objeto de referência em questão na securitização do Magreb-Sahel? O objetivo da militarização do Magreb-Sahel é realmente tanto no sentido de defender a civilização ocidental da ameaça terrorista quanto à estabilização de regimes autoritários para engajá-los posteriormente em processo político transformador, ou revela relações de poder e interesses geoestratégicos pouco aparentes?

A África está se tornando cada vez mais importante para a política externa dos EUA, devido à sua centralidade indubitável para os mercados energéticos globais (Mundy, 2010, p.9). Estimativas apontam que 25\% de importação do petróleo dos EUA virão da África até 2015 (Isidoro, 2010, p.64), já tendo ultrapassado a importância relativa do Oriente Médio. Com relação à região do Magreb-Sahel, seus países apresentam importantes recursos naturais, como petróleo, gás natural, fosfato, urânio, etc. Diversos analistas apontam para o fato de que a elevação do status geopolítico dessa região na GGT vai ao encontro dos interesses econômicos dos EUA, seja para o fluxo de recursos naturais, a competição cada vez mais acirrada com a China ou o estabelecimento de um mercado de livre-comércio vantajoso para seus produtos e investimentos (Entelis, 2008; Mundy, 2010; Toby \& Popovic, 2007; Harmon, 2010; Zoubir, 2008; Henry, 2008). O General Charles Wald, ex-comandante do EUCOM e arquiteto do PSI, afirmou em certa ocasião a centralidade das questões energéticas da África para os EUA: "If you look at the Gulf of Guinea, for example, and the oil revenues, and the hydrocarbons that are going to come out of there over the next 10 , 12 years, it's going to be more than we get out of the Middle East" (apud Henry, 2010, 
p.309). Por fim, conforme sugere Isidoros (2010), faz sentido a observação do nexo entre o terrorismo e os interesses econômicos:

\begin{abstract}
[e]ntrenched in these US actions is 'economic fundamentalism': by investing in the creation and maintenance of 'instability', thereby creating 'insecurity' to scaffold a vast-profit-making 'security' industry and secure economicpolitical dominance of the region. It is therefore in US interests to scriptwrite a mythology of terror onto a Saharan Landscape (p.67).
\end{abstract}

Se é verdade que tais interesses estão no cerne da presença e da militarização cada vez maiores dos EUA na região, a securitização do Magreb-Sahel permite, conforme discutido ao longo do trabalho, antes de tudo que regimes autoritários da região se utilizem da ameaça terrorista para reprimir a oposição e justificar medidas de exceção, permanecendo no poder indeterminadamente, ou até a eclosão de um golpe militar, como no caso do Mali. Às potências ocidentais, ficam garantidos, dessa forma, o acesso aos recursos e a manutenção de uma situação de estabilidade benéfica aos seus interesses estratégicos. As causas da radicalização das oposições islâmicas, bem como os fatores que alimentam conflitos regionais (nos quais gradativamente se acentua a atuação de grupos terroristas islâmicos como o Ansar Dine, o MUJAO ou a AQMI) e impossibilitam qualquer alternativa pacífica e democrática para a região acabam, contudo, negligenciados.

\title{
Referências Bibliográficas
}

Archer, Toby e Popovic, Tihomir. 2007. "The Trans-Saharan Counter-Terrorism Initiative: The US war on terrorism in North Africa". Finnish Institute of International Affairs. Disponível em: http://www.fiia.fi/en/publication/11/the trans-saharan counter-terrorism initiative/. Acesso em: 05/02/2013.

Buzan, Barry. 2006. "Will the 'Global War on Terrorism' be the new Cold War?". International Affairs, vol. 82, 1101-1118. DOI: 10.1111/j.1468-2346.2006.00590.x Acesso em: 10/04/2013

Buzan, Barry e Wæver, Ole. 2009. "Macrosecuritization and Security Constelations: reconsidering scale in securitization theory". Review of International Studies, vol. 35, 253-276. Disponível em:

http://journals.cambridge.org/action/displayAbstract?fromPage=online\&aid=5502088\&fulltex tType=RA\&fileld=S0260210509008511 Acesso em: 05/01/2013. 
Dennison, Susi. 2012. "The EU, Algeria and the Northern Mali question". European Council on Foreign Relations, n. 69. Disponível em:

http://ecfr.eu/content/entry/the eu algeria and the northern mali question. Acesso em: 10/04/2013.

Entelis, John P. 2008. "Democratic Desires and the Authoritarian Temptation in the Central Maghreb". In North Africa: politics, region, and the limits of transformation, editado por Yahia Zoubir e Haizam Amirah-Fernández, 9-30. Nova York: Editora Routledge.

Feldman, Gregory. 2005. Essential Crisis: A Performative approach to Migrants, Minorities, and the European Nation-state. Anthropological Quarterly, vol. 78, n. 1, 213-246. Disponível em: http://muse.jhu.edu/login?auth=0\&type=summary\&url=/journals/anthropological quarterly/v 078/78.1feldman.pdf. Acesso em: 02/01/2013.

Global Security. s/d. Pan Sahel Initiative (PSI). Disponível em:

http://www.globalsecurity.org/military/ops/pan-sahel.htm. Acesso em: 04/11/2012

Harmon, Stephen. 2010. "From GSPC to AQIM: The evolution of na Algerian Islamist terrorist group into an Al-Qa'ida Affiliate and its implications for the Sahara-Sahel region." In US militarization of the Sahara-Sahel Security, Space \& Imperialism, Concerned Africa Scholars, Boletim no 85, 12-29. Disponível em: http://concernedafricascholars.org/docs/bulletin85.pdf Acesso em: 05/11/2012.

Henry, Clement M. 2008. "Reverberations in the Central Maghreb of the "Global War on Terror."' In North Africa: politics, region, and the limits of transformation, editado por Yahia Zoubir e Haizam Amirah-Fernández, 294-310. Nova York: Editora Routledge.

Isidoros, Konstantina. 2010. "Western Sahara and the United States' geographical imaginings." In US militarization of the Sahara-Sahel Security, Space \& Imperialism, Concerned Africa Scholars, Boletim no 85, 63-71. Disponível em: http://concernedafricascholars.org/docs/bulletin85.pdf. Acesso em: 05/11/2012.

ISS. 2012. "Mali - faire la paix en préparant la guerre". I'Institut d'Etudes de Sécurite, n. 1. Disponível em: http://www.issafrica.org/pgcontent.php?UID=31876. Acesso em: 26/03/2013.

Lohmann, Annette. 2011. "Who Owns the Sahara? Old Conflicts, New Menaces: Mali and the Central Sahara between the Tuareg, Al Qaida and Organized Crime". Friedrich-Ebert-Stiftung. Disponível em: http://library.fes.de/pdf-files/bueros/nigeria/08181.pdf. Acesso em: 10/04/2013.

Mundy, Jacob. 2010. "Introduction: Securitizing the Sahara". In US militarization of the SaharaSahel Security, Space \& Imperialism, Concerned Africa Scholars, Boletim no 85, 1-11. Disponível em: http://concernedafricascholars.org/docs/bulletin85.pdf. Acesso em: 05/11/2012.

Mundy, Jacob. 2013. "Securitization or Terrorization? US counterterrorism policy and the crisis in the Sahara-Sahel". Pambazuka News. Disponível em: http://www.pambazuka.org/en/category/features/86564. Acesso em 10/04/2013.

Novotný, Daniel et al. 2011. "The Changing Security Situation in the Maghreb". Association for International Affairs, research paper no 3. Disponível em: http://www.anatem.info/articles/securite maghreb.pdf. Acesso em: 01/04/2013 
Novotný, Daniel; Belhaj, Abdessamad; Čejka, Marek; Savovová, Alice e Kužvart, Jean. 2011. The Changing Security Situation in the Maghreb. Associação de Relações Internacionais, artigo de pesquisa no3, Abril.

$\emptyset$ steb $\varnothing$, Terje. 2012. Islamic Militancy in Africa. Africa Security Brief, Africa Center for Strategic Studies, №. 23, novembro de 2012. Disponível em http://africacenter.org/2012/11/islamicmilitancy-in-africa/. Acessado em: 10/04/2013.

Pecequilo, Cristina S. 2011. A Política Externa dos Estados Unidos. Porto Alegre: Editora UFRGS, 3 a ed. atualizada e ampliada.

Sanders \& Moseley. 2012. A Political, Security and Humanitarian Crisis: Northern Mali. CivilMilitary Fusion Centre, julho. Disponível em: https://www.cimicweb.org/cmo/medbasin/Holder/Documents/r018\%20CFC\%20Monthly\%20T hematic\%20Report\%20(18-July-12).pdf. Acessado em: 10/04/2013.

Solà-Martín, Andreu. 2009. "Conflict Resolution in Western Sahara." African Journal on Conflict Resolution, vol. 9, n. 3, 117-40. Disponível em:

http://www.ajol.info/index.php/ajcr/article/viewFile/52181/40807. Acesso em: 28/04/2012.

Storm, Lise. 2009. "The Persistence of Authoritarianism as a source of radicalization in North Africa". International Affairs, vol. 85, n. 5, 997-1013. Disponível em: http://studium.unict.it/dokeos/2011/courses/1001283C0/document/storm IA2009.pdf.

Acesso em: 05/04/2013

Tanno, Grace. 2003. "A contribuição de Escola de Copenhague aos Estudos de Segurança Internacional". Revista Contexto Internacional, vol. 25, n. 1, 47-80. Disponível em: http://www.scielo.br/pdf/cint/v25n1/v25n1a02.pdf. Acesso em: 04/04/2013

Teixeira, Tatiana. 2007. Os think tanks e sua influência na política externa dos EUA. Rio de Janeiro: Editora Revan.

Théroux-Bénoni, Lori-Anne. 2013. Le Mali au lendemain de l'opération militaire française: Nouvelles opportunités ou rétour à la case départ? Institute d'Etudes de Sécurité - Analyse de Situation, 25/02/2013. Disponível em: http://www.cerium.ca/Le-Mali-au-lendemain-de-l. Acessado em: 10/04/2013.

Thurston, Alex. 2010. "Counterterrorism and democracy promotion in the Sahel under Presidents George W. Bush and Barack Obama from September 11, 2001, to the Nigerien Coup of February 2010." In US militarization of the Sahara-Sahel Security, Space \& Imperialism, Concerned Africa Scholars, Boletim no 85, 51-62. Disponível em: http://humansecuritygateway.com/documents/ACAS USMilitarizationoftheSaharaSahel Secur itySpaceandImperialism.pdf. Acesso em: 04/11/2012.

Tv5 Monde. s/d. Menaces sur le Mali - l'emission spéciale de TV5 Monde. Disponível em: http://www.youtube.com/watch?v= XDDlorqRZE. Acessado em: 17/03/2013.

Visacro, Alessandro. 2009. Guerra Irregular: terrorismo, guerrilha e movimentos de resistência ao longo da história. São Paulo: Editora Contexto. 
Wæver, Ole. 1995. 'Securitization and Desecuritization', in: Ronnie D. Lipschutz (ed.) On Security (New York: Columbia University Press), 46-85.

Wæver, Ole. 2007. "Securitization and Desecuritization." In International Security: Widening Security. Editado por Barry Buzan e Lene Hansen. Londres: Editora Sage, vol. 3, 66-98.

Weinraub, Bernard. 2001. The Moods They Are A'Changing In Films: Terrorism is Making Government Look Good. Disponível em: <http://www.nytimes.com/2001/10/10/movies/themoods-they-are-a-changing-in-films-terrorism-is-making-government-look-good.html $>$ Acesso em: 24/03/2013.

Zoubir, Yahia. 2008. "The United States, Islamism, Terrorism, and Democracy in the Maghreb: Predominance of Security?" In North Africa: politics, region, and the limits of transformation, editado por Yahia Zoubir e Haizam Amirah-Fernández, 266-293. Nova York: Editora Routledge.

Zoubir, Yahia. 2009. "The United States and Maghreb-Sahel Security." International Affairs, vol. 85, n. 5, 977-95. Disponível em: http://www.chathamhouse.org/sites/default/files/public/International\%20Affairs/2009/85 5z oubir.pdf. Acesso em: 01/11/2012. 